\title{
PIONEERING CONTRIBUTIONS OF PETER SAFAR TO INTENSIVE CARE AND THE FOUNDING OF THE SOCIETY OF CRITICAL CARE MEDICINE*
}

\author{
M. H. Weil, W. C. Shoemaker
}

Institute of Critical Care Medicine Palm Spring, California, USA

During the Crimean War, Florence Nightingale, the parent of professional nursing, segregated the most severely injured soldiers and bedded them in close proximity to the nursing station. This perhaps represented the beginning of intensive care. During the poliomyelitis epidemics in Scandinavia of 1949 and 1952 and, subsequently, during the polio epidemic of 1948 and 1949 in Los Angeles, special respiratory units were organized for bag ventilation of patients with bulbar polio. Excepting postanesthesia recovery units first implemented by Dandy in 1923 at the Johns Hopkins Hospital, which evolved more fully during the Second World War, there were no intensive care units as we know them today until 1958 [1].

Almost concurrently, although with somewhat differing emphasis, Weil and Shubin at the University of Southern California School of Medicine and the Los Angeles County General Hospital and Safar at the Baltimore City Hospital developed the first physician-staffed medical and surgical units for management of patients with immediately life-threatening conditions [2,3]. The Los Angeles team was co-headed by two cardiologists, Weil and his life-long collaborator, the late Dr. Herbert Shubin, and Chief Surgeon Leonard Rosoff. It was initially named the Shock Ward because its initial emphasis was on acute circulatory failure. Peter Safar's unit was identified as an «intensive care» unit, with major emphasis on management of the airway and on breathing, following the tradition of Dandy [4]. Both in the Los Angeles and in the Baltimore units, there was 24-hr/day, 7 -day/wk physician commitment to the care of the most seriously ill and injured by a multidisciplinary team representing both medical and surgical specialties. The goal of both units was fuller commitment to lifesaving care for the most seriously ill and injured, with primary emphasis on breathing, circulation, neurologic recovery, and control of infection. Both were committed to clinical and laboratory research, although the focus of the research of the Eastern and the Western centers was quite different. The Los Angeles team focused on an understanding of mechanisms of acute life-threatening illnesses and injuries [5-7]. Accordingly, it pioneered the development of monitoring and measuring devices. Equipment, including recorders, transducers, cuvettes, and thermocouples were taken from the physiology laboratory to the bedside. Central venous and arterial catheterization for pressure and cardiac output measurements by dye dilution techniques, measurements of central and peripheral body temperatures, detection and quantitation of life-threatening cardiac arrhythmias based on electrocardiographic heart rate and pulse rate, and respiratory frequency were implemented. The University of Southern California unit was a joint project of the departments of medicine and surgery and included isotopic methods for measurements of plasma and red cell volumes, especially for detection of hypovolemic shock. The «STAT Laboratory» concept was born in Los Angeles for rapid, «point of care» measurements of blood gases, electrolytes, and arterial blood lactate [8]. As early as 1960, the University of Southern California unit began to implement, primitive, digital computer methods for data management and bedside display [9]. Peter Safar's unit maintained early emphasis on the airway and ventilation, in part an extension of the Safar-initiated priorities in 1957 of the A and B of cardiopulmonary resuscitation, including Peter's singular commitment to that of saving lives by demonstrating options for better management of the airway and breathing and for pharmacologic interventions $[10,11]$. Peter was an early proponent of titrated therapy. He and his associates maintained early emphasis on ventilation, cardiopulmonary resuscitation, and neurologic outcomes in addition to the other priorities of the modern anesthesiologist. The University of Southern California group emphasized circulation, including acute myocardial infarction, sepsis, and drug overdoses. In the years that followed, however, interest in circulation gained momentum in Pittsburgh and ventilation in Los Angeles.

In 1961, both units began the first fellowship programs in what emerged as critical care medicine. The initial leaders of the field came from these programs, and our graduates literally populated new centers all over the globe and constitute a new generation of critical care leaders.

* Статья перепечатывается по согласованию с авторами. Статья опубликована в журнале «Сritical Care Medicine» 2004, V. 32, No 2 (Suppl. Care). 8-10. 
In 1962, surgeon William Shoemaker began what became one of the first trauma units in the United States at the Cook County Hospital in Chicago [12]. Shoemaker had been trained in surgical physiology at the Peter Bent Hospital in Boston by the famed Dr. Francis Moore and in biochemistry by Baird Hastings, the Harvard University giant of the field. In that setting, Shoemaker's interest included hemorrhagic shock and its complications and the hemodynamic and metabolic consequences of injury [13].

It was at a meeting of the Federated Societies in Atlantic City and during a casual walk on the famed boardwalk that Safar, Shoemaker, and Weil first shared concepts and aspirations on the care of patients with life-threatening conditions. Cardiologist/physiologist Weil, anesthesiologist/ resuscitation-leader Safar, and surgeon/physiologist Shoemaker found a commonality of concepts and goals. Peter was already well armed and, in fact, experienced in identifying the need for a more appropriate system, beginning with out-of-hospital emergency care. He promoted triage and stabilization of patients at the site, competent management during prehospital transport, preparedness for direct admission to the hospital emergency area, and orderly passage through preanesthesia, operation, and postoperative recovery. To Peter, the rational extension of this system was that of intensive postoperative care in either or both postoperative recovery and intensive care units. Peter also had a keen appreciation . for the diversity of disease states that were not exclusively in the domain of the anesthesiologist, including drowning, life-threatening bronchoconstriction, coma and vegetative states, and out-ofhospital cardiopulmonary resuscitation. Weil and Shubin both had a background in cardiorespiratory physiology. Weil had his residency and fellowship training at the University of Minnesota in the laboratories of the famed physiologist Maurice Visscher and infectious disease expert Wesley Spink. At the Mayo Clinic, Weil was under the tutelage of clinical physiologists Earl Wood and Ward Fowler and the famed cardiologist Howard Burchell. On the boardwalk in Atlantic City, the appropriateness of the multidisciplinary commitment to patient care by three academic doctors from diverse specialties became a bond. This multidisciplinary commitment to acute care emphasized the patient but also recognized the huge implications for acute care education and research.

Like comrades in arms, Safar, Shoemaker, and Weil maintained continuing dialog over the ensuing months, and their discussions culminated in meetings initially in Los Angeles in February 1970 in conjunction with the Eighth Annual Course on Critical Care Medicine and Shock, sponsored by the University of Southern California School of Medicine and its division of critical care medicine chaired by Weil. In July of 1970, the three initiators and their associates expanded to a group of 28 invited American medical leaders from diverse specialties. The intent was to propose an organization that became the Society of Critical Care Medicine. At the Ninth Annual Course on Critical Care Medicine and Shock in Los Angeles in February and later that year in May of 1971 at a course directed by Peter and the Department of Anesthesiology of the University of Pittsburgh, the Society was formally inaugurated with 100 members. Dr. Aki Grenvik, Peter's student and colleague, was a major contributor to the initial success of Society of Critical Care Medicine as chairman of the membership committee. Weil was elected as the first president and began the tradition of what became annual presidential addresses [14]. Safar was the second president and Shoemaker was the third president. In January of 1973, strongly supported by Safar and Weil, Shoemaker became the founding editor of Critical Care Medicine, now the leading journal in the field, worldwide, in critical and intensive care. We defer to our colleagues who contributed to this special issue of Critical Care Medicine to cite the remarkable achievements of Peter Safar, our friend, colleague, and leader. They will appropriately speak about Peter's extraordinary breadth of interest and involvement. The innovative and pioneering contributions of Peter started with resuscitation. The A, B, and subsequently, $\mathrm{A}, \mathrm{B}$, and $\mathrm{C}$ of cardiopulmonary resuscitation were Peter's. They will speak of the extraordinary humanism of Peter that complemented and reinforced his contributions to education, science, and practice. Peter Safar's home discipline was clinical anesthesia and its day-to-day practice. However, it was always in the context of saving lives. His involvement in prehospital emergency care of patients extended all the way from the site of intake to discharge from intensive care. He helped pioneer disaster care. His humanism was exemplary and courageous. He would risk his reputation to foster even politically unpopular proposals that would save lives - always respecting lives, but also the need for gently guiding patients out of life when there was no longer capability to maintain meaningful life. A workaholic by his own description, he was a beloved mentor and an academic parent to so many, including medical students, residents, fellows, and professional nurses. To his colleagues, he was a compassionate friend, a collaborator, and respectful combatant and, ultimately, a conciliatory compromiser.

Peter had visualized a comprehensive system of acute care that, as cited above, would start at the prehospital site of injury, illness, or disaster, provide for initial stabilization before transport and entry into the hospital, triage and emergency management on arrival, orderly transfer to the operating room or intensive care unit, and all of these under the umbrella of «resuscitation» or the French model of «reani- 
mation». Stimulated by the extraordinary respect he had for the contributions of his Russian colleague and friend, Professor Negovsky, Peter regarded himself as a resuscitation physician $[15,16]$. Peter most persuasively sought to combine emergency medicine, intensive care, and disaster and rescue medicine as one discipline. The name critical care medicine, synonymous with intensive care medicine, was in part from the title of a 1966 monograph authored by Dr. Stephen Ayres, entitled «The Care of the Critically III» [17], and from the name of the 42-bed Center for the Critically III, which was the 1967 successor unit of the Los Angeles University of Southern California Shock Ward [18]. Peter, during the years that followed, remained committed to the ultimate unification of emergency, disaster, and critical care medicine under a single multidisciplinary specialty umbrella. However, critical care medicine became a subspecialty, and emergency medicine ultimately became a separate primary specialty [19].

Peter Safar's autographic memoir speaks beautifully of the unique achievements of this great man [14]. Of the two remaining of the trio of critical care

\section{Литература}

1. Mizok B. Д., Weil M. H. Introduction: History and destiny of critical care medicine. In: Carlson R. W., Geheb M. A. (Eds). Principles and practice of medical intensive care. Philadelphia: W. B. Saunders; 1993.

2. Weil M. H., Shubin H., Rosoff L. Fluid repletionin circulatory shock: Central venous pressure and other practical guides. J. A. M. A. 1965; 192: 668-674.

3. Safar P., DeKornfeld T. J., Person J. M. The intensive care unit Anesthesia 1961; 16: 275.

4. Weil M. H., Shubin H., Rand W. Experiencewith a digital computer for study and improved management of the critically ill. J. A. M. A. 1966; 198: $147-152$

5. Sambhi M. P., Weil M. H., Udhoji V. N. Pressorresponses to norepinephrine in humans before and after corticosteroids. Am. J. Physiol. 1962 203: 961-963.

6. Udhoji V. N., Weil M. H., Sambhi M. P., et al. Hemodynamic studies on clinical shock associated with infection. Am. J. Med. 1963; 34: 461-469.

7. Weil M. H., Shubin H. Changes in venous capacitance during cardiogenic shock. Am. J. Cardiol. 1970; 26: 613.

8. Weil M. H., Michaels S., Puri V. K. et al. The Stat laboratory: Facilitating blood gas and biochemical measurements for the critically ill and injured. Am. J. Clin. Pathol. 1981; 76: 34-42.

9. Jensen R. E., Shubin H., Meagher P. F. et al. On-line computer monitoring of the seriously ill patient. Med. Biol. Eng. 1966; 4: 265-272.

10. Safar P., Escarraga L., Elam J. A comparisonof the mouth-to-mouth and mouth-to-airway methods of artificial respiration with the chest-pressure arm-lift methods. N. Engl. J. Med. 1958; 258: 671-677. initiators, we were blessed by admiration and professional friendships that existed among the three of us during our professional lifetimes. We shared destinies for $>35$ yrs. As we mourn Peter's passing, we perceive it as a painful and personal loss. However, his wondrous hold on life, always moving forward against odds and in so many spheres, fortified us all. The extraordinary qualities of this giant are best described in his own words: «The impossible is simply a greater challenge». One of us (M. H. Weil) had the privilege of maintaining close contact with him in the last year when, with the compassionate closeness and support of his wife, Eva, overwhelming cancer and infection would not dampen Peter's spirit His extraordinary commitment to life and unrelenting spirit to move forward against impossible physical odds of pain and disability were with vigor, decorum, and even charm and, most remarkably, without even a complaint. We will do well to commit ourselves to keep our eye on the horizon projected by Peter, for it extends beyond our individual identities as physicians and even beyond the Society which he served so well.

11. Safar P. Ventilatory efficacy of mouth-to-mouth artificial respiration: Airway obstruction during manual and mouth-to-mouth artificial respiration. J. A. M. A. 1958; 167: 335-341.

12. Shoemaker W. C., Montgomery E. S., Kaplan E. et al. Physiologic patterns in surviving andnonsurviving shock patients: Use of sequential cardiorespiratory variables in definingcriteria for therapeutic goals and early warning of death. Arch. Surg. 1973; 106: 630-636.

13. Shoemaker W. C., Printen K.J., Amato J.J. et al. Hemodynamic patterns after acute anesthetized and unanesthezed. trauma: Evaluation of the sequence of changes in cardiac output and derived calculations. Arch. Surg. 1967; 95: 492-499.

14. Weil M. H. Presidential address: The society of critical care medicine, its history and its destiny. Crit. Care Med. 1973; 1: 1-4.

15. Safar P. J. From Vienna to Pittsburgh for anesthesiology and acute medicine: An autobiography. In: Fink B. R., McGoldrick K. E. (Eds). ParkRidge I. L.: Careers in anesthesiology. 5. Wood Library-Museum of Anesthesiology; 2000.

16. Negovsky V.A. Current problems of reanimation. Daniel Skup (Trans), Creighton. HC (Ed.). M.: Mir Publishers; 1975.

17. Ayers S. M. Giannelli S. Jr. Care of the critically 111. N. Y. : AppletonCentury-Crofts; 1967.

18. Weil M. H., Shubin H. Centers for the critically ill: Symposium on the care of the critically ill. Mod. Med. 1971; 39: 83-85.

19. Weil M. H., Shoemaker W. C., Rackow E. C. Competent and continuing care of the critically ill and injured. Crit. Care Med. 1988; 16: 298.

Поступила 14. 09. 2006 